\title{
Atriplex nummularia como alternativa alimentar para frangos Caipira Francês
}

\author{
"Atriplex nummularia" as alimentary alternative to French free-range Broiler
}

\author{
BARRETO, Viviane Nunes Souza ${ }^{1 *}$; MENEZES, Daniel Ribeiro ${ }^{1}$; PEREIRA, Luiz \\ Gustavo Ribeiro²; ARAÚJO, Gherman Garcia Leal de Araújo ${ }^{3}$; SILVA, Aldrin Ederson \\ Vila Nova'; SOUSA, Luciano Nunes ${ }^{1}$; BARBOSA, Aynoanne Leandro ${ }^{1}$; COSTA, \\ Jonathan Maia da Silva ${ }^{1}$; MOREIRA, Rafaele Ferreira ${ }^{1}$
}

\author{
${ }^{1}$ Universidade Federal do Vale do São Francisco, Colegiado de Medicina Veterinária, Petrolina, \\ Pernambuco, Brasil. \\ ${ }^{2}$ Embrapa Gado de Leite, Juiz de Fora, Minas Gerais, Brasil. \\ ${ }^{3}$ Embrapa Semiárido, Petrolina, Pernambuco, Brasil. \\ *Endereço para correspondência: vns19.1@hotmail.com
}

\section{RESUMO}

Objetivou-se avaliar com este trabalho a utilização da erva-sal (Atriplex nummularia) irrigada com o resíduo da dessalinização, como alternativa alimentar em dietas para engorda de frangos Caipira Francês. Aos 28 dias de idade, foram selecionados, de forma individual e por peso, 120 frangos (60 machos e 60 fềmeas) que foram distribuídos em delineamento inteiramente casualizado, com quatro tratamentos, cinco repetições e seis aves por unidade experimental. As dietas experimentais foram isonutritivas e formuladas à base de feno da parte aérea da mandioca (FM), feno de Atriplex (FA), milho em grão moído e farelo de soja. Foram utilizados quatro tratamentos: $0 \% ; 35 \% ; 65 \%$; e $100 \%$ de substituição do FM pelo FA na ração base. Não houve diferença significativa para o consumo de matéria seca, consumo de proteína bruta e consumo de energia bruta em relação à substituição do FM pelo FA que apresentaram médias de 133,9g/ave/dia, 19,8g/ave/dia e $543,3 \mathrm{Kcal} /$ ave/dia, respectivamente. A conversão alimentar das dietas testadas obteve comportamento linear crescente. Com substituição de $17,7 \%$ do FM pelo FA podem-se obter ganhos máximos de $432,4 \mathrm{~g}$ e $14,4 \mathrm{~g} /$ dia, respectivamente para ganho médio total e diário. A substituição do FM pelo FA em intervalo de 46,4 a 50\% apresentou melhores resultados para peso de carcaça e valores econômicos nas dietas testadas.

\section{SUMMARY}

This work aimed to evaluate a utilization of the Salt brush (Atriplex nummularia) irrigated with residue from desalination as an alternative to Caipira French chickens' fattening diet. Hundred twenty chickens (60 males and 60 females), 28 day old, were selected individually away and by body weight and were distributed in a complete randomized design with four treatments, five repetitions and six chickens by experimental unit. Experimental diets were isonutritious and formulated by cassava hay $(\mathrm{CH})$, Atriplex hay $(\mathrm{AH})$, corn grain and soybean meal. It was used four treatments: $0 \%$, $35 \%, 65 \%$ and $100 \%$ with replacement of $\mathrm{CH}$ by the $\mathrm{AH}$ in the base feed. There was no significant difference amount the intake of dry matter, crude protein and gross energy in relation to the replacement of $\mathrm{CH}$ by the $\mathrm{AH}$ who presents media of $133.9 \mathrm{~g} /$ chicken/day, $19.8 \mathrm{~g} /$ chicken/day and $543.3 \mathrm{Kcal} /$ chicken/day respectively. The feed gain ratio of the diets tested had linearly increased. With a $17.7 \%$ replacement of $\mathrm{CH}$ by $\mathrm{AH}$ can be obtained maximum gains of $432.4 \mathrm{~g}$ and $14.4 \mathrm{~g} / \mathrm{day}$, respectively for total and daily average gain. The replacement of $\mathrm{CH}$ by the $\mathrm{AH}$ in the range from 46.4 to $50 \%$ showed better results for carcass weight and economic value in diets.

Keywords: aviculture, fiber, salinity, semiarid

Palavras-chave: avicultura, fibra, salinidade, semiárido 


\section{INTRODUÇ̃̃O}

A região semiárida do Nordeste brasileiro possui uma grande área de manancial de água salobra subterrânea. O crescente uso da dessalinização de água pelo processo de osmose inversa poderá trazer impactos ambientais severos, em função do elevado teor de sais que é despejado no solo através deste processo tecnológico. O plantio de espécies resistentes ao sais (halófitas), como a erva-sal (Atriplex nummularia Lindl.) é uma opção de aproveitamento do concentrado salino devido aos mecanismos de tolerância à salinidade e potencial forrageiro que possuem essas espécies, o que as tornam uma importante fonte de nutrientes (PORTO et al., 2006).

Dentre as halófitas cultiváveis para fins de forragem, as espécies do gênero Atriplex L. mostram-se como alternativas viáveis para a região semiárida. Espécies deste gênero têm sido introduzidas com sucesso em solos com altos níveis de salinidade, inclusive alguns resultados já foram obtidos em experimentação com ruminantes (BEN SALEM et al., 2010), porém, ainda não existem relatos de sua utilização em dietas para aves, mais especificamente, frangos de corte.

A produção de frangos de corte no semiárido está relacionada com a agricultura familiar e apresenta-se como alternativa alimentar e econômica em propriedades rurais (SILVA et al., 2003; RODRIGUES et al., 2006), inclusive nos assentamentos da reforma agrária e em alguns pequenos municípios nordestinos.

O frango de corte, assim como outros animais monogástricos, é fonte de alimentos para o homem (NEPOMUCENO et al., 2011; SCOTTÁ et al., 2011), e é capaz de transformar produtos de origem vegetal em proteína de alta qualidade, o que promove melhoria nos índices nutricionais da população inserida na região semiárida.

No sistema de produção de aves, a alimentação corresponde a aproximadamente 65 a $70 \%$ do custo total. Dessa forma, torna-se importante buscar alimentos alternativos que apresentem adaptação às características edafoclimáticas e que reduzam os custos da atividade; (RAMOS et al., 2006).

Neste contexto, a realização deste trabalho teve como objetivo avaliar a erva-sal (Atriplex nummularia) irrigada com o resíduo da dessalinização como alternativa alimentar em dietas para frangos de corte Caipira Francês.

\section{MATERIAL E MÉTODOS}

O experimento foi desenvolvido no período de junho a agosto de 2010. Foram utilizados 120 frangos de corte da raça Caipira Francês, 50\% machos e 50\% fêmeas, com 28 dias de idade, selecionados individualmente de acordo com o peso médio do lote, distribuídos em delineamento inteiramente casualizado, com quatro tratamentos, cinco repetições e seis aves por unidade experimental, durante a fase de 29 a 75 dias de idade.

As aves foram alojadas em um galpão experimental de $120 \mathrm{~m}^{2}$, em cama de maravalha de aproximadamente cinco centímetros de espessura do solo. Foram utilizados bebedouros e comedouros pendulares.

As aves receberam água e ração à vontade durante todo o período experimental e o fornecimento de ração foi diário, com mudanças na sua composição de acordo com a idade das aves.

As dietas experimentais foram isonutritivas, à base de feno da parte aérea da mandioca (FM), feno de 
Atriplex (FA), milho em grão moído (MM) e farelo de soja (FS), formuladas para atenderem as exigências das aves de acordo com recomendações do NRC (1994). Foram utilizados quatro tratamentos: $0 \% ; 35 \% ; 65 \%$; e $100 \%$ de substituição do feno de mandioca pelo feno de Atriplex na ração basal (Tabela 1).

A Atriplex e a mandioca, com idade aproximada de um ano e seis meses, respectivamente, foram colhidas no campo experimental da caatinga na
EMBRAPA Semiárido. As plantas foram passadas em máquina forrageira $\mathrm{e}$ sofreram processamento da fenação. Para a elaboração das rações, foi determinada, nos laboratórios da UNIVASF e da EMBRAPA Semiárido, a composição química e bromatológica dos alimentos, de acordo com a metodologia descrita em Silva \& Queiroz (2002). Posteriormente, os alimentos foram misturados, nas proporções referentes aos tratamentos, e obtiveram-se desta forma, as dietas completas.

Tabela 1. Participação dos ingredientes nas dietas e composição química do feno de Atriplex (FA), feno da parte aérea da mandioca (FM), farelo de soja (FS), milho moído (MM) e das dietas experimentais caracterizadas pela substituição do feno de mandioca pelo feno de Atriplex na ração base

\begin{tabular}{|c|c|c|c|c|c|c|c|c|}
\hline \multirow{2}{*}{\multicolumn{5}{|c|}{ Participação do ingrediente (\%) }} & \multicolumn{4}{|c|}{ Níveis de substituição (\%) } \\
\hline & & & & & 0 & 35 & 65 & 100 \\
\hline Feno de Atriplex & & & & & 00 & 07 & 13 & 20 \\
\hline Feno da parte aérea da ma & dioca & & & & 20 & 13 & 07 & 00 \\
\hline Farelo de soja & & & & & 30 & 30 & 30 & 30 \\
\hline Milho moído & & & & & 50 & 50 & 50 & 50 \\
\hline \multirow{2}{*}{ Parâmetros } & & Ingre & entes & & \multicolumn{4}{|c|}{ Níveis de substituição (\%) } \\
\hline & FA & FM & FS & $\mathrm{MM}$ & 0 & 35 & 65 & 100 \\
\hline Matéria seca (\%) & 88,2 & 87,1 & 89,4 & 90,6 & 88,8 & 88,6 & 88,1 & 87,9 \\
\hline Proteína bruta $(\%)^{*}$ & 13,5 & 18,5 & 49,7 & 8,3 & 17,7 & 17,7 & 17,5 & 18,1 \\
\hline Extrato etéreo $(\%)^{*}$ & 1,5 & 2,2 & 2,1 & 3,7 & 2,9 & 2,9 & 2,8 & 2,8 \\
\hline Fibra bruta $(\%)^{*}$ & 22,8 & 21,6 & 7,2 & 2,84 & 5,0 & 5,8 & 6,0 & 8,7 \\
\hline Energia bruta $(\mathrm{Kcal} / \mathrm{Kg})^{*}$ & 3468 & 3849 & 4204 & 4518 & 3682 & 3651 & 3812 & 3752 \\
\hline
\end{tabular}

As variáveis de desempenho analisadas foram o consumo de ração (CR), o ganho de peso (GP) e a conversão alimentar (CA), além dos cortes comerciais e da viabilidade econômica no final do experimento.

O consumo de ração foi calculado por diferença entre a quantidade de ração fornecida e as sobras diárias, e obtido pela divisão do consumo acumulado e total da parcela pelo número de aves da parcela, e assim foi verificado o consumo médio de ração por ave do $29^{\circ}$ ao $75^{\circ}$ dias, em gramas. O ganho de peso foi determinado pela diferença entre o peso das aves no início e no fim do período experimental. A partir dos dados de consumo de ração/ganho de peso, foi calculado a conversão alimentar dos animais. A viabilidade foi calculada individualmente por parcela, pelo número de aves alojadas no dia 29 e o número de aves vivas no dia 75 , expressa em porcentagem. 
Ao final do período experimental (75 dias de idade) as aves foram pesadas e submetidas a um período de jejum de oito horas, sacrificadas por sangria da veia jugular, depenadas, evisceradas e após pesagem da carcaça, foram submetidos cortes comerciais das asas e coxas (sem sobrecoxas).

Foram avaliados os pesos das carcaças, dos cortes supracitados e dos órgãos comestíveis (coração, fígado e moela). Os constituintes não carcaça, como sangue, cabeça e pés, também foram pesados.

$\mathrm{O}$ estudo da viabilidade econômica da substituição do feno de mandioca pelo feno de erva-sal na ração foi realizado conforme relatado por Ramos et al. (2006). Para tal consideraram-se as seguintes variáveis primárias: consumo médio de ração (CMR, kg), custo da ração $(\mathrm{CR}, \mathrm{kg})$, ganho de peso médio (GPM, kg), peso vivo médio (PVM, kg) e preço do frango vivo (PFV, $\mathrm{kg}$ ). Com base nos valores observados para essas variáveis primárias foram obtidos os seguintes indicadores econômicos: custo médio de alimentação (CMA) = CMR x CR, relação CMA/GPM, renda bruta média $(\mathrm{RBM})=\mathrm{PVM} \times \mathrm{PFV}$, margem bruta média $(\mathrm{MBM})=\mathrm{RBM}-$ CMA.

Calculou-se a margem bruta (MB), considerando-se: $\mathrm{MB}=(\mathrm{kg}$ frango produzido x preço de venda do frango) - (preço da ração x ração consumida), envolvendo os preços dos ingredientes constantes nas rações.

$\mathrm{O}$ peso vivo foi obtido pelo peso médio dos frangos antes do jejum, aos 75 dias de idade. O preço médio do quilo do frango caipira vivo $(\mathrm{R} \$ 4,00)$ foi pesquisado no comércio da região de Petrolina-PE e procedeu-se uma média em relação ao preço evidenciado no Brasil. Enquanto que o preço do quilo da ração $(\mathrm{R} \$ 0,71)$ foi considerado a partir dos preços de pesquisa das rações comerciais e de confecção dos fenos no período de Janeiro/Agosto de 2010.

As análises de variância, teste Tukey a $5 \%$ e regressão (linear e quadrática) foram realizadas por meio do programa estatístico SAS - Statistic Analysis System 9.1 (SAS INSTITUTE, 2003). Os modelos foram escolhidos com base na significância dos coeficientes de regressão, e utilizou-se o teste $\mathrm{t}$, a $1 \mathrm{e}$ $5 \%$ de probabilidade.

\section{RESULTADOS E DISCUSSÃO}

O feno de Atriplex (FA) e o feno da parte aérea da mandioca (FM) apresentaram teores semelhantes em todos os parâmetros avaliados, com exceção apenas da proteína bruta (Tabela 1), a qual se apresentou maior para o feno da parte aérea da mandioca.

A composição bromatológica das dietas experimentais apresentou valores aproximados para todos os parâmetros (Tabela 1). Este resultado já era esperado, visto que as dietas foram formuladas para serem todas isonutritivas.

Não houve diferença significativa para o consumo de matéria seca (CMS), consumo de proteína bruta (CPB) e consumo de energia bruta (CEB) em relação à substituição do feno da parte aérea da mandioca pelo feno de Atriplex (Tabela 2). Estas variáveis apresentaram médias de 133,9g/ave/dia, 19,8g/ave/dia e $543,3 \mathrm{Kcal} /$ ave/dia, respectivamente.

Segundo Mertens (1994), frações fibrosas na dieta geram incremento calórico com a fermentação e, consequentemente, possíveis perdas energéticas. No presente trabalho, mesmo com aumento no consumo de fibra devido à inclusão de erva-sal, não houve aumento no consumo de energia para compensar possíveis perdas. Isso pode ser justificado pelo fato 
dos valores de energia dos fenos serem relativamente baixos, além das aves apresentarem deficiência no aproveitamento de alimentos fibrosos em função da sua baixa capacidade de fermentação desse tipo de alimento pelo seu sistema digestório, mais especificamente, no intestino grosso.
O consumo da FB obteve comportamento quadrático em relação às inclusões de erva-sal nas dietas (Tabela 2) e apresentou ponto máximo, pela estimativa da equação obtida, de 15,4 g/ave/dia em substituição de $70,5 \%$ do feno de mandioca pelo feno de erva-sal.

Tabela 2. Médias dos consumos de matéria seca (CMS), da proteína bruta (CPB), da fibra bruta (CFB), da energia bruta (CEB) e da água $\left(\mathrm{CH}_{2} \mathrm{O}\right)$, além da conversão alimentar (CA), equações de regressão (ER), coeficientes de determinação $\left(\mathrm{R}^{2}\right)$ e significância (p) de acordo com níveis de substituição de $0 \%, 35 \%, 65 \%$ e $100 \%$ de feno de Atriplex (FA) por feno da parte aérea da mandioca (FM)

\begin{tabular}{|c|c|c|c|c|c|c|c|}
\hline \multirow{2}{*}{ Item } & \multicolumn{4}{|c|}{ Níveis de substituição (\%) } & \multirow{2}{*}{ ER } & \multirow{2}{*}{$\mathrm{R}^{2}$} & \multirow{2}{*}{$\mathrm{p}$} \\
\hline & 0 & 35 & 65 & 100 & & & \\
\hline \multicolumn{8}{|c|}{ Consumo de Nutrientes } \\
\hline CMS (g/ave/dia) & $139,6^{\mathrm{a}}$ & $136,3^{\mathrm{a}}$ & $137,4^{\mathrm{a}}$ & $122,1^{\mathrm{a}}$ & $Y=133,9$ & - & ns \\
\hline CPB (g/ave/dia) & $18,1^{\mathrm{a}}$ & $18,3^{\mathrm{a}}$ & $25,4^{\mathrm{a}}$ & $17,6^{\mathrm{a}}$ & $\mathrm{Y}=19,8$ & - & ns \\
\hline CFB (g/ave/dia) & $3,2^{\mathrm{a}}$ & $6,1^{\mathrm{a}}$ & $21,0^{\mathrm{c}}$ & $11,1^{\mathrm{b}}$ & 1 & 0,51 & $*$ \\
\hline CEB (Kcal/ave/dia) & $569,6^{\mathrm{a}}$ & $531,5^{\mathrm{a}}$ & $565,7^{\mathrm{a}}$ & $506,3^{\mathrm{a}}$ & $Y=543,3$ & - & ns \\
\hline $\mathrm{CH}_{2} \mathrm{O}$ (ml/ave/dia) & $370,2^{\mathrm{a}}$ & $458,1^{\mathrm{b}}$ & $464,0^{\mathrm{b}}$ & $440,0^{\mathrm{b}}$ & 2 & 0,41 & $*$ \\
\hline $\mathrm{CA}$ & $9,90^{\mathrm{a}}$ & $9,80^{\mathrm{a}}$ & $11,47^{\mathrm{b}}$ & $19,02^{\mathrm{c}}$ & 3 & 0,51 & $*$ \\
\hline
\end{tabular}

*significativo a $1 \%$ pelo teste $\mathrm{t}$; $\mathrm{ns}=$ não significativo.

Letras diferentes na mesma linha diferem estatisticamente a $1 \%$ pelo Teste Tukey.

$1: Y=1,48+0,395 x-0,0028 x^{2} ; C V=10,0 \% ; 2: Y=372,3+3,116 x-0,0246 x^{2} ; C V=11,7 \% ; 3: Y=8,135+0,0882 x$; $\mathrm{CV}=9,0 \%$.

Este resultado pode estar relacionado ao alto nível de fibra nas rações, visto que o máximo de fibra permitido nas dietas para aves é de $6 \%$ (NRC, 1994), e com o nível de substituição de $70,5 \%$ de feno de Atriplex (FA) por feno da parte aérea da mandioca (FM) o nível de fibra apresenta-se próximo ou além deste valor (Tabela 1), o que proporcionou às aves o baixo aproveitamento da fibra e dos nutrientes da ração.

$\mathrm{O}$ consumo de água $\left(\mathrm{CH}_{2} \mathrm{O}\right)$ também obteve comportamento quadrático em relação às inclusões de erva-sal nas dietas (Tabela 2), que apresentou, pela estimativa da equação, consumo máximo de 470,9 ml/ave/dia na substituição de $63,3 \%$. Este incremento no consumo de água em detrimento ao consumo de fibra bruta, pode ser explicado, em parte, pelo efeito da capacidade de hidratação das moléculas da parede celular, tanto as fibras solúveis quanto insolúveis (MERTENS, 1994), como também pelo aumento na participação do Atriplex nas dietas, que devido aos altos teores de sais (PORTO et al., 2006), pode ter estimulado o consumo hídrico pelos animais. Desta forma as aves consumiram mais água quando ingeriram mais feno de Atriplex 
e, consequentemente, mais fibra disponível na ração.

A conversão alimentar obteve comportamento linear crescente com a substituição do feno da parte aérea da mandioca pelo feno da erva-sal (Tabela 2 e Figura 1). A cada substituição de 15\% de erva-sal observa-se piora de $1,32 \%$ na conversão alimentar.

a)

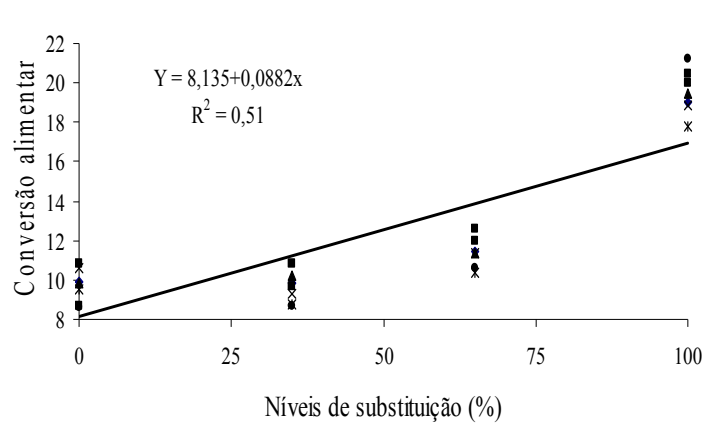

c)

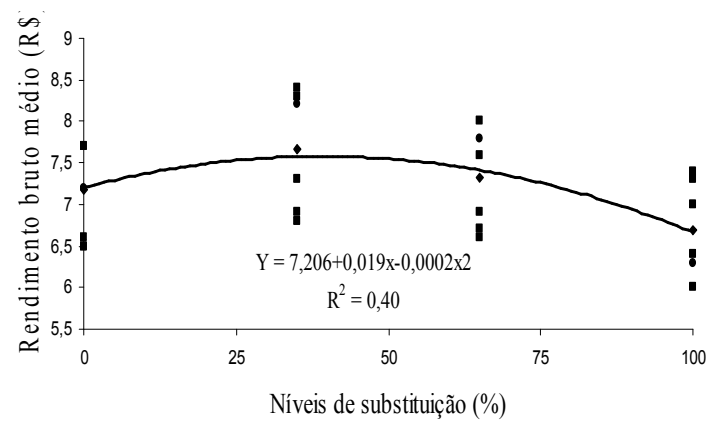

Como a conversão alimentar para frangos de corte é obtida a partir da relação entre o consumo de ração (g/ave/dia) e a ganho de peso (g/ave/dia), pode-se afirmar que esse incremento, ou seja, piora na conversão alimentar, está relacionada ao decréscimo do ganho de peso médio diário (GMD) com o aumento do nível de inclusão de feno de Atriplex.

b)

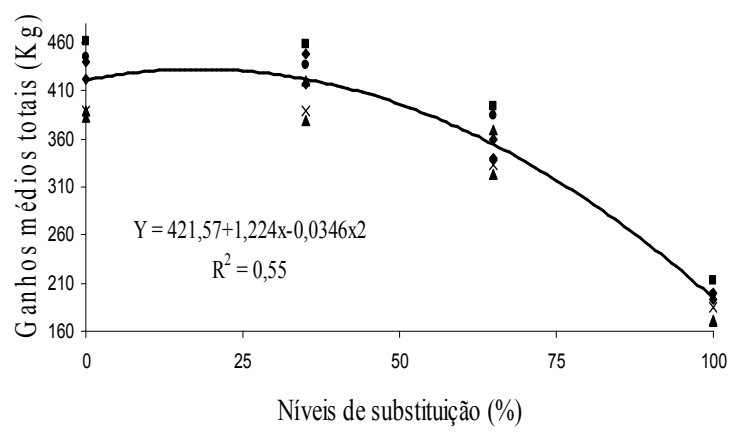

d)

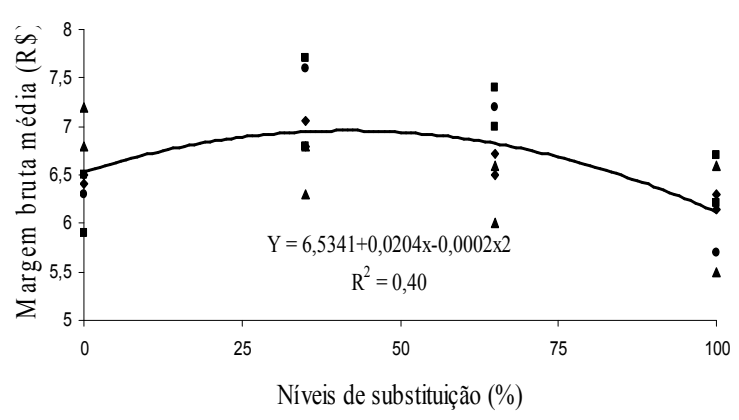

Figura 1. Conversão alimentar (a), ganhos médios totais (b), rendimento bruto médio (c) e margem bruta média (d) de acordo com níveis de substituição de $0 \%, 35 \%$, $65 \%$ e $100 \%$ de FM por FA

As dietas propostas não apresentaram diferenças significativas para as variáveis sangue (SAN), cabeça (CAB), pés, vísceras (VISC), fígado (FIG), coração (COR), coxas (COXA) e asas, que apresentaram valores médios de 12,30 ; 37,$30 ; 34,10 ; 628,00 ; 16,35 ; 4,25 ; 283,05$; e 76,90 gramas, respectivamente.

$\mathrm{O}$ peso vivo final (PVF) apresentou influência significativa da substituição do feno da parte aérea da mandioca pela erva-sal como fontes de fibra (Tabela 3). Houve comportamento quadrático e aumento dos valores até $1894,43 \mathrm{~g}$ que representa uma substituição de 39,0\%. Após esse nível de substituição houve um decréscimo no peso vivo final. Este resultado está relacionado ao alto nível de fibra nas rações, valor evidenciado na ração com substituição a partir de 
Rev. Bras. Saúde Prod. Anim., Salvador, v.13, n.1, p.214-223 jan/mar, 2012 http://www.rbspa.ufba.br ISSN 15199940

$35 \%$ de feno de Atriplex por feno da parte aérea da mandioca (Tabela 1). A partir desse valor de fibra, ocorre interferência direta na diminuição da absorção de nutrientes, em consequência da diminuição do tempo de permanência do alimento no trato gastrintestinal (SUNDU et al., 2006), o que influencia no desempenho do animal.

Tabela 3. Médias das variáveis peso vivo inicial (PVI), peso vivo final (PVF), ganho médio total (GMT), ganho médio diário (GMD), sangue (SAN), cabeça (CAB), pés, vísceras (VISC), fígado (FIG), coração (COR), coxas (COXA), asas, equações de regressão (ER), coeficientes de determinação $\left(\mathrm{R}^{2}\right)$ e significância (p), de acordo com níveis de substituição de FM por FA

\begin{tabular}{|c|c|c|c|c|c|c|c|}
\hline \multirow{2}{*}{ Item } & \multicolumn{4}{|c|}{ Níveis de substituição (\%) } & \multirow{2}{*}{ ER } & \multirow{2}{*}{$\mathrm{R}^{2}$} & \multirow{2}{*}{$\mathrm{p}$} \\
\hline & 0 & 35 & 65 & 100 & & & \\
\hline PVI (g) & $1372,40^{\mathrm{a}}$ & $1496,91^{\mathrm{a}}$ & $1472,94^{\mathrm{a}}$ & $1480,38^{\mathrm{a}}$ & $Y=1455,66$ & - & $\mathrm{ns}$ \\
\hline $\operatorname{PVF}(\mathrm{g})$ & $1795,36^{\mathrm{ab}}$ & $1914,27^{\mathrm{a}}$ & $1832,33^{\mathrm{ab}}$ & $1673,00^{\mathrm{b}}$ & 1 & 0,35 & $*$ \\
\hline GMT(g) & $422,96^{\mathrm{a}}$ & $417,36^{\mathrm{a}}$ & $359,40^{\mathrm{a}}$ & $192,62^{\mathrm{b}}$ & 2 & 0,55 & $*$ \\
\hline GMD (g) & $14,098^{\mathrm{a}}$ & $13,912^{\mathrm{a}}$ & $11,978^{\mathrm{a}}$ & $6,420^{\mathrm{b}}$ & 3 & 0,55 & $*$ \\
\hline SAN (g) & $11,60^{\mathrm{a}}$ & $12,80^{\mathrm{a}}$ & $12,40^{\mathrm{a}}$ & $12,40^{\mathrm{a}}$ & $Y=12,30$ & - & $\mathrm{ns}$ \\
\hline $\mathrm{CAB}(\mathrm{g})$ & $26,20^{\mathrm{a}}$ & $26,40^{\mathrm{a}}$ & $26,60^{\mathrm{a}}$ & $30,00^{\mathrm{a}}$ & $Y=27,30$ & - & ns \\
\hline PÉS (g) & $34,20^{\mathrm{a}}$ & $34,20^{\mathrm{a}}$ & $34,80^{\mathrm{a}}$ & $33,20^{\mathrm{a}}$ & $Y=34,10$ & - & $\mathrm{ns}$ \\
\hline CARC (g) & $623,00^{\mathrm{ab}}$ & $683,00^{\mathrm{ab}}$ & $695,00^{\mathrm{a}}$ & $591,00^{\mathrm{b}}$ & 4 & 0,35 & $*$ \\
\hline VISC (g) & $552,00^{\mathrm{a}}$ & $676,00^{\mathrm{a}}$ & $660,00^{\mathrm{a}}$ & $608,00^{\mathrm{a}}$ & $Y=628,00$ & - & ns \\
\hline MOEL (g) & $36,00^{\mathrm{b}}$ & $40,40^{\mathrm{ab}}$ & $44,20^{\mathrm{a}}$ & $40,30^{\mathrm{ab}}$ & 5 & 0,25 & * \\
\hline FIG $(g)$ & $15,00^{\mathrm{a}}$ & $16,80^{\mathrm{a}}$ & $17,40^{\mathrm{a}}$ & $16,20^{\mathrm{a}}$ & $Y=16,35$ & - & $\mathrm{ns}$ \\
\hline $\operatorname{COR}(\mathrm{g})$ & $3,80^{\mathrm{a}}$ & $4,40^{\mathrm{a}}$ & $4,40^{\mathrm{a}}$ & $4,40^{\mathrm{a}}$ & $Y=4,25$ & - & $\mathrm{ns}$ \\
\hline COXA (g) & $276,60^{\mathrm{a}}$ & $299,60^{\mathrm{a}}$ & $297,60^{\mathrm{a}}$ & $258,40^{\mathrm{a}}$ & $Y=283,05$ & - & $\mathrm{ns}$ \\
\hline ASAS (g) & $72,80^{\mathrm{a}}$ & $79,00^{\mathrm{a}}$ & $83,00^{\mathrm{a}}$ & $72,80^{\mathrm{a}}$ & $Y=76,90$ & - & ns \\
\hline
\end{tabular}

*significativo a $1 \%$ pelo teste $t ; n s=$ não significativo.

Letras diferentes na mesma linha diferem estatisticamente a $1 \%$ pelo Teste Tukey.

$1: Y=1801,6+4,767 x-0,0612 x^{2} ; C V=12,8 \% ; 2: Y=421,57+1,224 x-0,0346 x^{2} ; C V=7,8 \% ; 3: Y=14,05+0,042 x-$ $0,0012 \mathrm{x}^{2} ; \mathrm{CV}=8,0 \% ; 4: \mathrm{Y}=620,03+3,3438 \mathrm{x}-0,036 \mathrm{x}^{2} ; \mathrm{CV}=14,0 \% ; 5: \mathrm{Y}=35,659+0,231 \mathrm{x}-0,0018 \mathrm{x}^{2} ; \mathrm{CV}=13,7 \%$.

Esonu et al. (2002), ao analisarem o desempenho e utilização dos nutrientes de frangos de corte na fase de terminação, alimentados com rações que continham 0 , 10 e $15 \%$ do feno da folha de Microdesmis puberula, observaram que com o nível de $15 \%$ de inclusão de feno, as aves apresentaram baixo ganho de peso, piora na conversão alimentar $\mathrm{e}$ redução na digestibilidade da matéria seca, do nitrogênio e do extrato etéreo. Esses resultados foram atribuídos ao aumento do teor de fibra da ração, que, consequentemente, diminui a capacidade das aves de aproveitarem a energia e os nutrientes da dieta.

A substituição do feno da parte aérea da mandioca pela erva-sal apresentou comportamento quadrático em relação aos ganhos de peso médio total $\mathrm{e}$ diário (Tabela 3 e Figura 1). Com substituição de $17,7 \%$ podem-se obter ganhos máximos de 432,4g e 14,4g/dia, respectivamente para GMT e GMD. 
Componentes não digestíveis como a fibra alimentar podem interferir no consumo de alimentos, bem como na digestibilidade e disponibilidade de energia e proteína inerentes ao crescimento de monogástricos, Le Goff et al. (2002). No presente estudo o teor de fibra bruta das dietas foi semelhante, porém os resultados obtidos para desempenho remetem à possibilidade da diferenciação nos constituintes da fração fibrosa da erva-sal e da parte aérea da mandioca. A erva-sal pode ter apresentado maiores porções indigestíveis e, portanto, estas podem ter gerado maior energia térmica alimentar (ETA) e consequentemente menor energia líquida para crescimento. Com isso, o incremento da erva-sal nas dietas pode ter reduzido o ganho de peso dos animais submetidos às dietas com substituições acima de 17,7\%.

A inclusão da erva-sal nas dietas proporcionou efeito quadrático sobre os pesos das carcaças (CARC) dos animais testados e apresentou o maior peso $697,7 \mathrm{~g}$ em substituição de $46,4 \%$ (Tabela 3).

A variável moela (MOEL) obteve comportamento quadrático em relação à substituição da parte aérea da mandioca pela erva-sal, com valor máximo de 38,3g para uma substituição de $23,0 \%$ (Tabela 3). Este comportamento pode ser explicado, em parte, pela característica da porção fibrosa das plantas testadas.

Uma das mais importantes funções da fibra está associada à habilidade em estimular a atividade da moela. Quando as aves se alimentam com rações que contêm um alto nível de fibra, a quantidade desta fração encontrada na moela chega a ser o dobro da quantidade presente no alimento ingerido $\mathrm{e}$ isso proporciona um aumento na atividade muscular da moela, o que causa uma hipertrofia na musculatura da mesma e, consequentemente, aumento no seu peso (HETLAND et al., 2005).

Não houve diferença estatística entre as dietas para as variáveis do custo médio de alimentação (CMA) e relação custo médio de alimentação e ganho de peso médio (CMA/GPM), que apresentaram valores médios de $0,61 \mathrm{R} \$ / \mathrm{kg}$ e $0,06 \mathrm{R} \$ / \mathrm{kg}$, respectivamente (Tabela 4).

Tabela 4. Médias dos indicadores econômicos custo médio de alimentação (CMA), relação custo médio de alimentação e ganho de peso médio (CMA/GPM), renda bruta média (RBM) e margem bruta média (MBM), das equações de regressão (ER), dos coeficientes de determinação $\left(\mathrm{R}^{2}\right)$ e da significância $(\mathrm{p})$, de acordo com níveis de substituição de 0, 35, 65 e 100\% de FM por FA

\begin{tabular}{|c|c|c|c|c|c|c|c|}
\hline \multirow{2}{*}{ Item } & \multicolumn{4}{|c|}{ Níveis de substituição (\%) } & \multirow{2}{*}{ ER } & \multirow{2}{*}{$\mathrm{R} 2$} & \multirow{2}{*}{$\mathrm{p}$} \\
\hline & 0 & 35 & 65 & 100 & & & \\
\hline CMA (R\$/kg) & $0,678^{\mathrm{a}}$ & $0,607^{\mathrm{a}}$ & $0,611^{\mathrm{a}}$ & $0,542^{\mathrm{a}}$ & $Y=0,610$ & - & ns \\
\hline CMA/GPM (R\$/kg) & $0,048^{\mathrm{a}}$ & $0,044^{\mathrm{a}}$ & $0,058^{\mathrm{a}}$ & $0,096^{\mathrm{a}}$ & $Y=0,062$ & - & ns \\
\hline $\mathrm{RBM}(\mathrm{R} \$)$ & $7,18^{\mathrm{ab}}$ & $7,66^{\mathrm{a}}$ & $7,33^{\mathrm{ab}}$ & $6,69^{b}$ & 1 & 0,40 & $*$ \\
\hline MBM (R\$) & $6,50^{\mathrm{ab}}$ & $7,050^{\mathrm{a}}$ & $6,72^{\mathrm{ab}}$ & $6,15^{\mathrm{b}}$ & 2 & 0,40 & $*$ \\
\hline
\end{tabular}

*significativo a $1 \%$ pelo teste $\mathrm{t}$; $\mathrm{ns}=$ não significativo.

Letras diferentes na mesma linha diferem estatisticamente a 1\% pelo Teste Tukey.

$1: Y=7,206+0,019 x-0,0002 x^{2} ; C V=13,0 \% ; 2: Y=6,5341+0,0204 x-0,0002 x^{2} ; C V=12,6 \%$. 
As variáveis, renda bruta média (RBM) e margem bruta média (MBM) obtiveram comportamento quadrático em relação aos níveis de substituição do feno de mandioca pela erva-sal (Figura 1). Substituição de aproximadamente $50 \%$ ocasionou valores máximos de $\mathrm{R} \$ 7,70$ e $\mathrm{R} \$ 7,10$ respectivamente.

Ramos et al. (2006) ao avaliarem a viabilidade econômica de frangos de corte alimentados com dietas que continham diferentes níveis de polpa de caju desidratada obtiveram valores médios aproximados de R\$5,30; $\mathrm{R} \$ 2,20 / \mathrm{kg} ; \mathrm{R} \$ 3,10$ para RBM, CMA e MBM, respectivamente.

A substituição do feno da parte aérea de mandioca pelo feno de erva-sal no intervalo de 46,4 a $50 \%$ apresentou melhores resultados para peso de carcaça e valores econômicos nas dietas testadas.

\section{REFERÊNCIAS}

BEN SALEM, H.; NORMAN, H.C.; NEFZAOUI, A.; MAYBERRY, D.E.; PEARCE, K.L.; REVELL, D.K. Potential use of oldman saltbush (Atriplex nummularia Lindl.) in sheep and goat feeding. Small Ruminant Research, $\mathrm{n}$ 91,p.13-28, 2010.

ESONU, B.O.; IHEUKWUMERE, F.C.; EMENALOM, O.O.; UCHEGBU, M.C.; ETUK, E.B. Performance, nutrient utilization and organ characteristics of broiler finishers fed Microdesmis puberula leaf meal. Livestock Research for Rural Development, v.14, n.2, p.15, 2002.

HETLAND, H.; SVIHUS, B.; CHOCT, $\mathrm{M}$. Role of insoluble fiber on gizzard activity in layers. Journal Applied Poultry Research, v.14. p.38 - 46, 2005.
LE GOFF, G.; DUBOIS, S.; VAN MILGEN, J.; NOBLET, J. Influence of dietary fibre level on digestive and metabolic utilization of energy in growing and finishing pigs. Animal Research, v.51, p.245-259, 2002.

MERTENS, D.R. Regulation of forage intake. In: FAHEY JUNIOR, G.C. (Ed). Forage quality, evaluation and utilization. Madison: American Society of Agronomy, 1994. p.450-493.

NEPOMUCENO, R.C.; CARVALHO, L.E.; FREITAS, E.R.; GOMES, T.R.; AQUINO, T.M.F.; ELLERY, E.A.C.; MOREIRA, R.H.R.; VIEIRA, J.J.F. Inclusão da quirera de arroz em rações de suínos na fase de creche. Revista Brasileira de Saúde e Produção Animal [Online], v.12, n.3, p.718-728, 2011.

NATIONAL RESEARCH COUNCIL NRC. Nutrient requirements of poultry. 9th revised ed. Washington: National Academy Press, 1994.

PORTO, E.R.; AMORIM, M.C.; DUTRA, M.T.; PAULINO, R.V.; BRITO, L.T.L.; MATOS, A.N.B. Rendimento da Atriplex nummularia irrigada com efluentes da criação de tilápia em rejeito da dessalinização de água. Revista Brasileira de Engenharia Agrícola e Ambiental, v.10, n.1, p.97-103, 2006.

RAMOS, L.S.N.; LOPES, J.B.; FIGUEIREDO, A.V.; FREITAS, A.C.; FARIAS, L.A.; SANTOS, L.S.; SILVA, H.O. Polpa de caju em rações para frangos de corte na fase final: desempenho e características de carcaça. Revista Brasileira Zootecnia, v.35, n.3, p.804-810, 2006. 
RODRIGUES, F.P.; QUEIROZ, S.A.; DUARTE, J.M.B. Genetic relatedness among wild, domestic and Brazilian fighting roosters. Brazilian Journal of Poultry Science, v.8, n.2, p.83-87, 2006.

\section{SAS INSTITUTE. Statiscs: user's} guide. Version 9,1. Cary, NC, 2003.

SCOTTÁ, B.A.; VARGAS JUNIOR, J.G.; PETRUCCI, F.B.; DEMUNER, L.F.; COSTA, F.G.P.; BARBOSA, W.A.; MARIN, J.F.V. Metionina mais cistina digestível e relação metionina mais cistina digestível: lisina para codornas japonesas. Revista Brasileira de Saúde e Produção Animal [Online], v.12, n.3, p.729-738, 2011.
SILVA, M.A.N.; HELLMEISTER

FILHO, P.; ROSÁRIO, M.F.;

COELHO, A.A.D.; SAVINO, V.J.M.;

GARCIA, A.A.F.; SILVA, I.J.O.; MENTEM, J.F.M.. Influência do sistema de criação sobre o desempenho, a condição fisiológica e o comportamento de linhagens de frangos de corte. Revista Brasileira de

Zootecnia, v.32, n.1, p.208-213, 2003.

SUNDU, B.; KUMAR, A.; DINGLE, J. Response of broiler fed increasing levels of copra meal and enzymes. International journal of Poultry Science, v.5, p.13 -18, 2006.

Data de recebimento: 15/09/2011

Data de aprovação: 30/01/2012

SILVA, D.J.S.; QUEIROZ, A.C. Análise de alimentos: métodos químicos e biológicos. Viçosa: Universidade Federal de Viçosa, 2002. $235 \mathrm{p}$. 